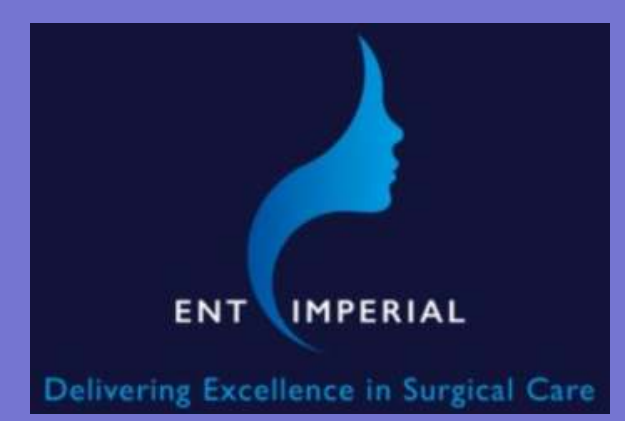

\title{
An unusual case of chronic mastoiditis due \\ to bone wax
}

\section{P.Kulloo, A.Parikh. St Mary's Hospital, London}

\section{Background}

Bone wax is considered a safe haemostatic agent in mastoidectomy. However, it has complications such as foreign body granuloma with sigmoid sinus thrombosis and delayed extrusion of bone wax through post-auricular wounds. ${ }^{1,2}$

\section{Objective}

We present an unusual case of chronic mastoiditis caused by a walled-off mastoid abscess due to bone wax used in previous mastoidectomy.

\section{Case}

Our patient with previous mastoidectomy and mastoid obliteration had a chronically discharging mastoid cavity. During mastoid exploration, a thick walled abscess was found. Following incision of the abscess wall, abundant pus and bone wax were removed.

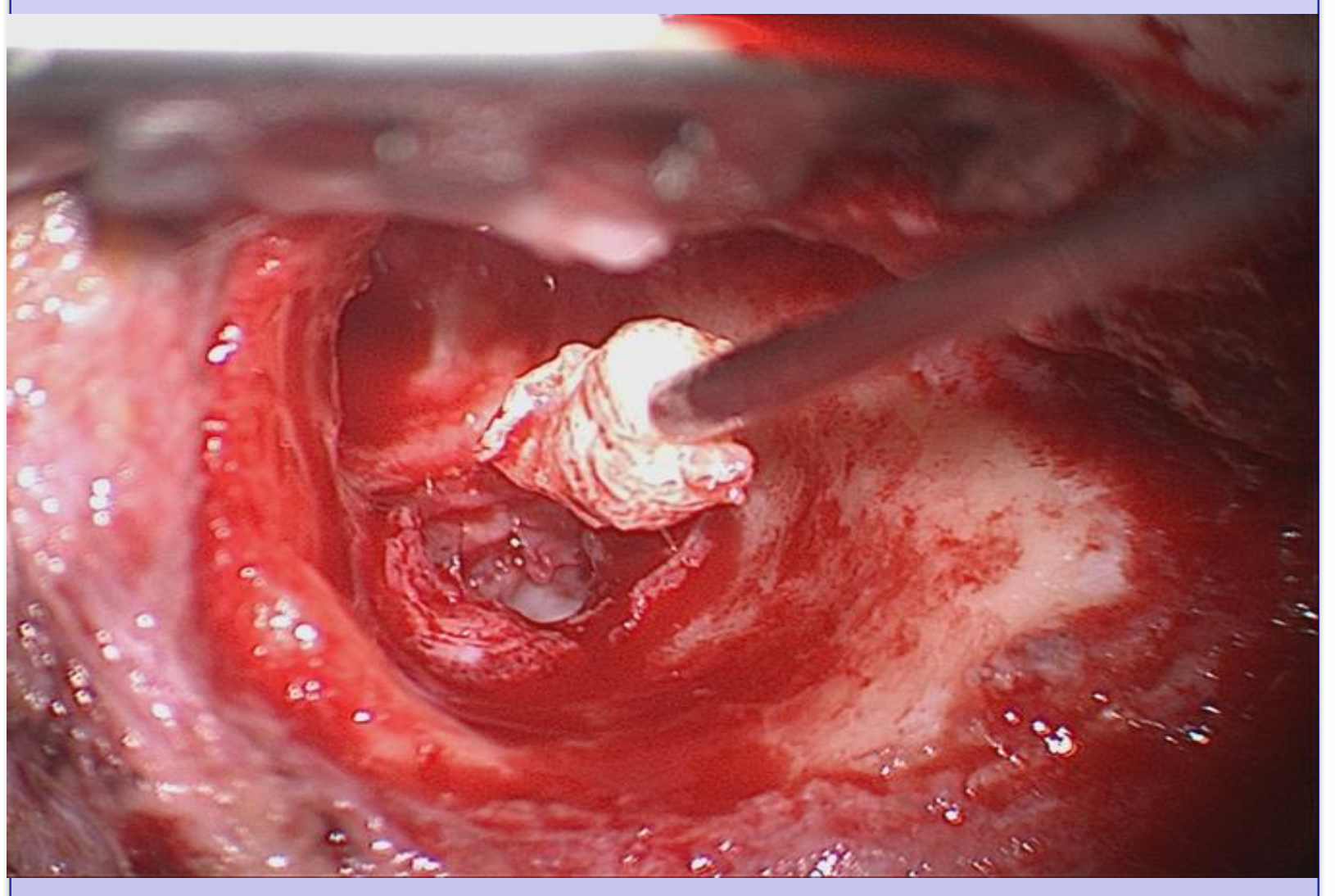

Image 1: Bone wax being removed from abscess cavity

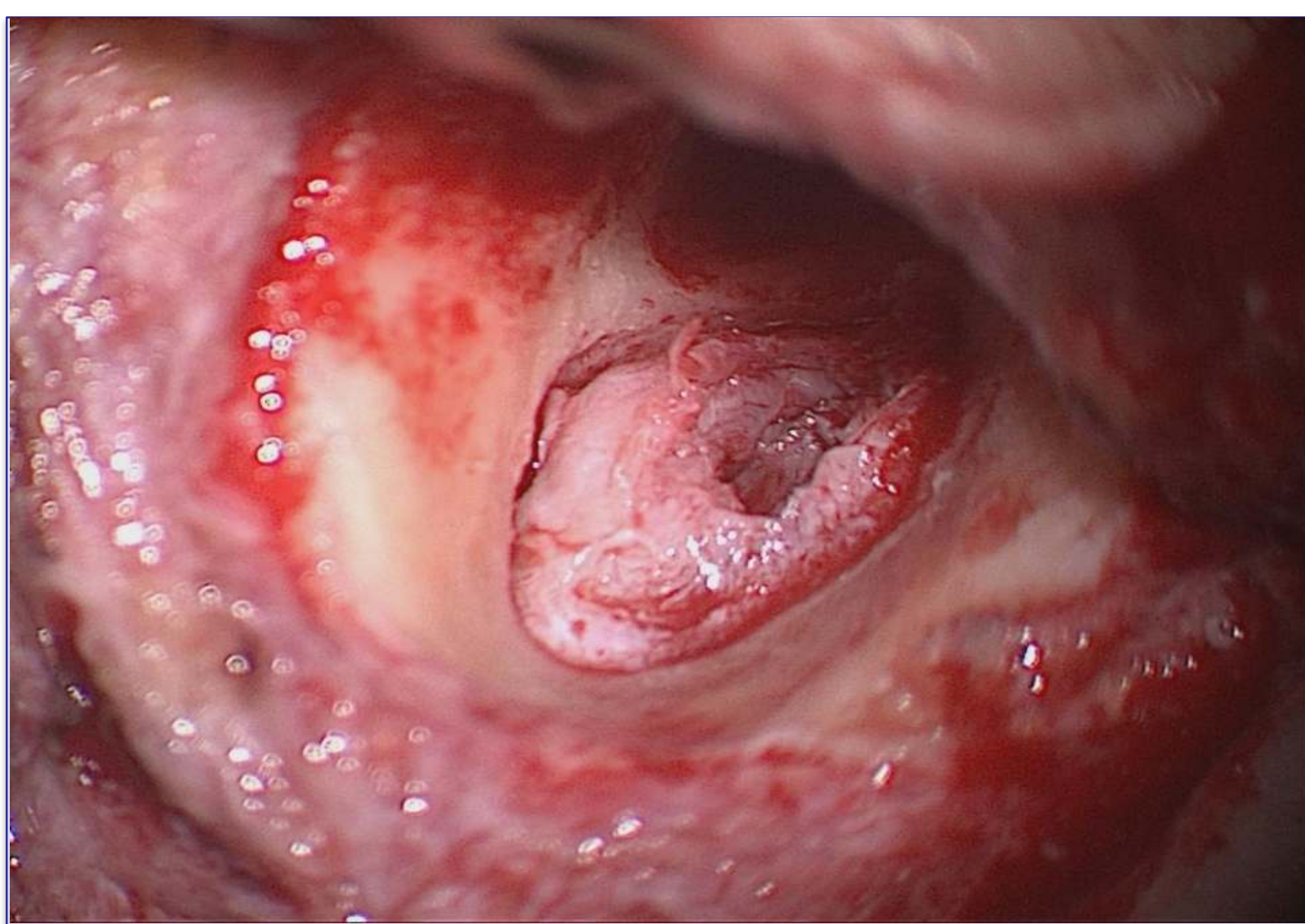

Image 2: Thick walled abscess cavity after pus and bone wax removed

The cavity was obliterated with demineralised bone matrix. The ear was dry at follow-up.

\section{Conclusion}

Although use of bone wax is generally safe, surgeons should be aware of its complications and should use it sparingly.

\section{References:}

1. Baird SM, Teh BM, Lim KKM, Campbell MC. Bone wax extrusion through postauricular wounds: A case series. Vol. 128, The Laryngoscope. United States; 2018. p. 369-72.

2. Low WK, Sim CS. Bone wax foreign body granuloma in the mastoid. ORL J Otorhinolaryngol Relat Spec. 2002;64(1):38-40. 